\title{
Stress Corrosion Cracking of Austenitic Stainless Steel Alloys for Reinforced Concrete
}

\author{
M. J. Correia ${ }^{1, a}$ and M. M. Salta ${ }^{1, b}$ \\ ${ }^{1}$ Laboratório Nacional de Engenharia Civil \\ Av. do Brasil, 101, 1700-066 Lisboa, Portugal. Ph. (351)218443000, Fax (351)218443023 \\ amjmcorreia@Inec.pt, ${ }^{\mathrm{b}} \mathrm{msalta@Inec.pt}$
}

Keywords: Stress corrosion cracking, corrosion prevention, austenitic stainless steel, slow strain rate test.

\begin{abstract}
The corrosion resistance under mechanical stress can be one of the most concerning types of localized corrosion for the application of stainless steel reinforcements in concrete. This paper will assess the stress corrosion cracking susceptibility, by the slow strain rate test method (SSRT), of three austenitic stainless steel alloys: one conventional Fe-Cr-Ni base alloy and two new composition $\mathrm{Fe}-\mathrm{Cr}-\mathrm{Mn}$ base alloys adequate to the manufacturing of ribbed bars for reinforcing concrete. The SSRT results show that only one of the austenitic Fe-Cr-Mn alloys is susceptible to stress corrosion cracking while the other shows a performance similar to that of the AISI 304 stainless steel alloy.
\end{abstract}

\section{Introduction}

The reinforcement steel corrosion is the most common cause of deterioration of concrete structures. The main consequences of reinforcement steel corrosion as well as its repercussions on the concrete durability are indicated in the literature [1-3]. The concrete favors the steel reinforcement passivation, however, over time, it can experience modifications that hinder this protection assurance. The spreading of the reinforcement corrosion problem foments the development of different forms of prevention, the corrosion prevention being considered as a crucial factor for a good performance of concrete structures [4]. In the last few years, several research studies indicate that the use of stainless steel reinforcement is a solution to achieve a maintenance free long life construction ( $>100$ years) $[5,6]$. Supported by several research studies, as it is a material more resistant to corrosion, stainless steel emerges as a complementary prevention measure. The main disadvantage associated with this preventive measure is its highest cost. However, the use of stainless steel in reinforced concrete will become more competitive with the development of new less costly stainless steel alloys, with similar mechanical properties and with equivalent corrosion resistance to those exhibited by the conventional Fe-Cr-Ni alloys.

Despite the highest corrosion resistance shown by stainless steel as a material that shows passivation characteristics, it remains susceptible to corrosion, mainly to localized corrosion. The simultaneous balance of several conditioning factors, such as microstructural, metallurgic and many different external factors, shows the complexity of localized corrosion interpretation. The catastrophic consequences of the stress corrosion occurrence particularly provide this subject with an essential importance. Despite the numerous works dedicated to this topic, the stress corrosion is a controversial subject which presents an enormous diversity of hypotheses and arguments. Therefore, it is difficult to predict the stress corrosion susceptibility of an alloy.

Since the corrosion under mechanical stress can be one of the most concerning types of localized corrosion for the application of stainless steel as reinforcement, this paper addresses the evaluation of the stress corrosion cracking (SCC) susceptibility of two new Fe-Cr-Mn austenitic alloys developed under the HIPER Project. The slow strain rate test (SSRT) has been the method used to assess the SCC susceptibility of these new alloys, being complemented with the fractographic 
analysis. The behavior of these new alloys is compared with the one of a conventional austenitic FeCr-Ni alloy (AISI 304).

\section{Experimental}

Materials. Three different austenitic stainless steel alloys were tested: AISI 304 stainless steel alloy, as smooth bars with $\phi 12 \mathrm{~mm}$, and, recently developed Fe-Cr-Mn stainless steel alloys (SS1 and SS2), as smooth bars with $\phi 14 \mathrm{~mm}$. Table 1 indicates the chemical composition of the different stainless steel alloys.

\begin{tabular}{|lcccccccccc|}
\cline { 2 - 10 } \multicolumn{1}{c|}{} & $\mathbf{N}$ & $\mathbf{C}$ & $\mathbf{C u}$ & $\mathbf{C r}$ & $\mathbf{S}$ & $\mathbf{P}$ & $\mathbf{M n}$ & $\mathbf{M o}$ & $\mathbf{N i}$ & $\mathbf{S i}$ \\
\hline AISI 304 & 0.07 & 0.06 & 0.43 & 17.5 & $<0.001$ & 0.025 & 1.19 & 0.53 & 8.54 & 0.38 \\
\hline SS1 & 0.20 & 0.08 & 2.18 & 16.2 & $<0.001$ & 0.015 & 7.92 & 0.08 & 0.21 & 0.17 \\
\hline SS2 & 0.28 & 0.06 & 2.28 & 16.9 & $<0.001$ & 0.006 & 8.62 & 2.08 & 1.59 & 0.23 \\
\hline
\end{tabular}

Table 1 - Chemical composition (weight percentage) of AISI 304, SS1 and SS2 stainless steel alloys determined by optical emission spectrometry.

Lab steel specimens were designed and prepared according to the international standard ISO 7539-4 [7]. Round bar specimens ( $108 \mathrm{~mm}$ long by $8 \mathrm{~mm}$ diameter) were machined from the rod samples of the stainless steel alloys and threaded on both ends for attachment (gauge section with $3.18 \mathrm{~mm}$ in diameter and $12.7 \mathrm{~mm}$ long).

Equipment. The slow strain rate test apparatus consists of a fixed stiff frame, a three phase asynchronous motor type C71B/4 (CEMP) with $0.50 \mathrm{cv}$, two speed reducers type MVC2 with 1/60 ratio, a gear wheel system, and a load cell type MVD 2405. For the acquisition of the applied load, potential and temperature during the tests, an automatic system of acquisition and storage Datataker 505 with DataloggerPro software was used.

For the half-cell potential measurements, a saturated calomel reference electrode and a Luggin salt bridge were used.

The fractographic analysis was done using a stereo microscope OLYMPUS SZH and a scanning electron microscope JEOL JSM-6400, with the electron beam energy at $15 \mathrm{KeV}$. The microstructures of the alloys were observed using the metalographic microscope PM3 OLYMPUS.

Procedure. The microstructural characterization of the three stainless steel alloys studied was performed, the grain size and the inclusion content being respectively done by comparison (ASTM E 112-96 [8]) and by the worst field method (ASTM E 45-97 [9]).

The general procedure for conducting the slow strain rate test was in compliance with the international standard ISO 7539-7 [10]. Prior to the experiments, the specimens were polished to 2500 grit with emery papers and degreased with acetone. Only the gauge zone was exposed, the gripped portion of the specimen being isolated from the corrosive test environment. For each type of stainless steel, SSRT were carried out at room temperature $\left(20 \pm 2{ }^{\circ} \mathrm{C}\right)$ under three different exposure conditions: in air, in dry air (with low relative humidity of approximately 4\%) and in saturated calcium hydroxide solution with $3 \%$ chlorides from sodium chloride addition (to simulate the condition in the concrete contaminated with chlorides). For the tests performed in solution, the $\mathrm{pH}$ of the solution was measured at the beginning and at the end of each test and the half-cell potential has been continuously measured during the test duration. Two crosshead rates were used in the SSRT $-8 \times 10^{-5} \mathrm{~mm} \mathrm{~s}^{-1}$ and $6 \times 10^{-6} \mathrm{~mm} \mathrm{~s}^{-1}$.

Both reduction of area and elongation measurements were performed on the tested specimens, by measuring the diameter and the length of the gauged section before and after the test. After each SSRT, a fractographic analysis was done.

\section{Results and Discussion}

Microstructural Characterization. Fig. 1 shows the microstructure of each stainless steel alloy tested, observed in cross sections. The AISI 304 stainless steel shows an austenitic matrix (ASTM grain size 4) with type B and type D aluminum oxide inclusions. The SS1 high manganese alloy 
shows an austenitic matrix (ASTM grain size 4) with disseminated ferrite platelets, type D globular aluminum oxides and type B alumina inclusions. The SS2 alloy presents an austenitic matrix (ASTM grain size 7) with some globular ferrite islands and type B, C and D inclusions. In all cases, the severity levels recorded were less than 2 for thin series, and less than 1 for heavy series.

Slow Strain Rate Tests and Fractographic Analysis. Fig. 1 also shows some examples of the tensile stress-time and potential-time curves obtained for each tested material.
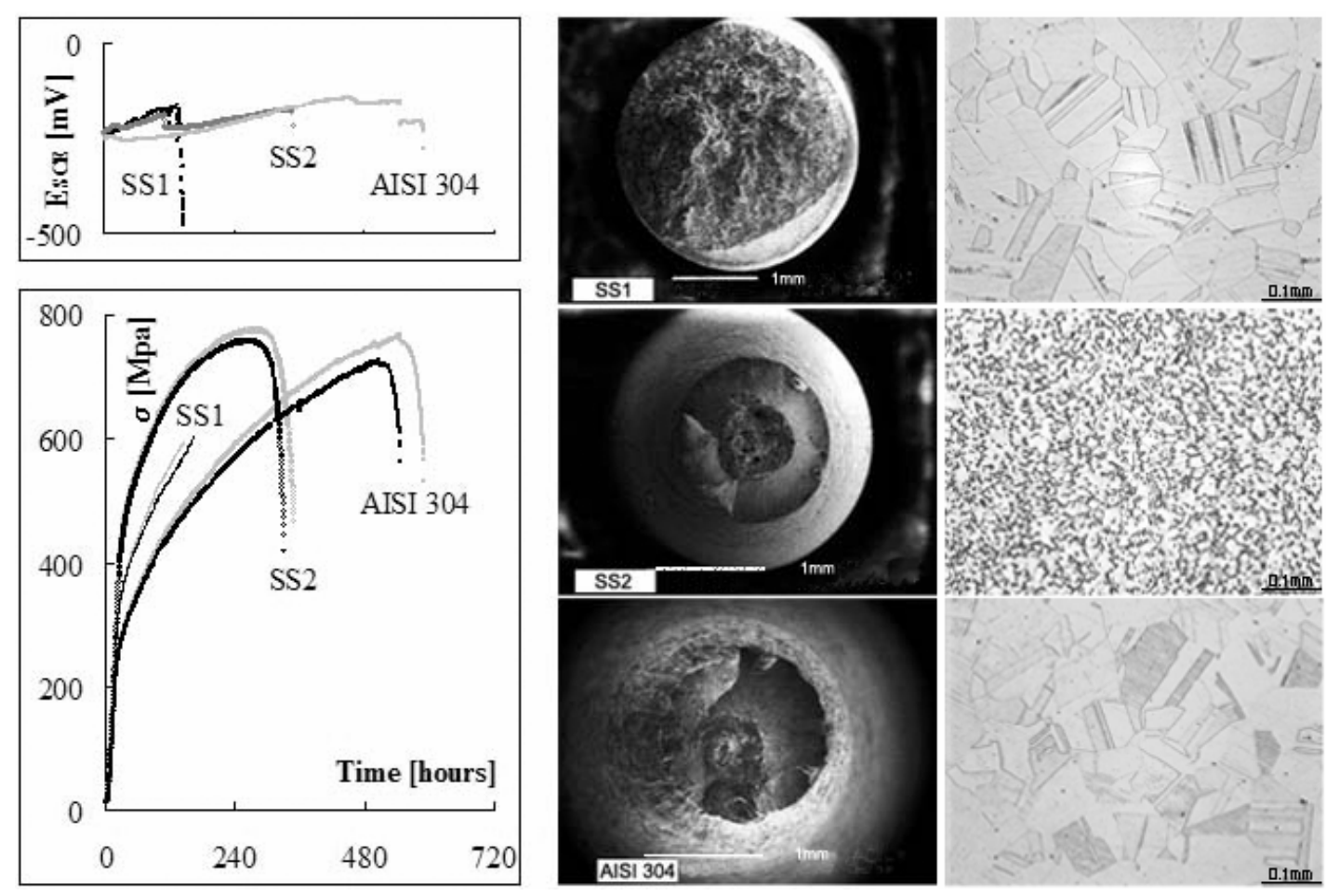

Figure 1 - Tensile stress-time curves and potential-time evolution from tests in air (black curves) and in a saturated $\mathrm{Ca}(\mathrm{OH})_{2}$ solution with $3 \% \mathrm{Cl}^{-}$(grey curves) at $6 \times 10^{-6} \mathrm{~mm} \mathrm{~s}^{-1}$ crosshead rate. SEM fractographs of stainless steel tensile specimens tested in solution. Microstructure in a cross section at $100 x$.

SCC resistance can be evaluated using the following parameters measured after SSRT: percentage of reduction of area, percentage of elongation to fracture and ultimate tensile strength. Table 2 presents these quantitative parameters obtained from the tests in a non corrosive environment (air) and in a corrosive medium (saturated $\mathrm{Ca}(\mathrm{OH})_{2}$ solution with chlorides), with the lowest crosshead rate. Similar results were obtained with the highest crosshead rate. With the exception of the SS1 alloy, the quantitative parameters for the tests in solution are higher than the corresponding values obtained in air. Comparing the tests for the SS1 stainless steel alloy done at a $8 \times 10^{-5} \mathrm{~mm} \mathrm{~s}^{-1}$ crosshead rate in dry air $\left(\mathrm{RA}=28 \% ; \varepsilon=35 \% ; \sigma_{\max }=768 \mathrm{MPa}\right)$ and in air $(\mathrm{RA}=19 \% ; \varepsilon=26 \%$; $\sigma_{\max }=620 \mathrm{MPa}$ ), there can be further verified that the decrease in relative humidity improved the performance of the alloy. Similar results were obtained for all the stainless steel alloys.

\begin{tabular}{|ccccccc|}
\hline \multirow{2}{*}{ Alloy } & \multicolumn{2}{c}{ RA [\%] } & \multicolumn{2}{c}{$\boldsymbol{\varepsilon}[\%]$} & \multicolumn{2}{c|}{$\sigma_{\max }[\mathrm{Mpa}]$} \\
& $\mathrm{A}$ & $\mathrm{S}$ & $\mathrm{A}$ & $\mathrm{S}$ & $\mathrm{A}$ & $\mathrm{S}$ \\
\hline SS1 & 31 & 19 & 25 & 21 & 628 & 596 \\
\hline SS2 & 76 & 79 & 49 & 51 & 762 & 778 \\
\hline AISI 304 & 73 & 80 & 81 & 88 & 728 & 770 \\
\hline
\end{tabular}

Table 2 - Results from SSRT in air (A) and in a saturated $\mathrm{Ca}(\mathrm{OH})_{2}$ solution with $3 \% \mathrm{Cl}^{-}(\mathrm{S})$ at $6 \times 10^{-6} \mathrm{~mm} \mathrm{~s}^{-1}$ crosshead rate. 
The comparative tests performed in air and in solution with the AISI 304 and SS2 show that each of these alloys has an analogous behaviour in the two environments (Fig. 1), which is characteristic of a ductile rupture. Based on the tensile-time curves and on the quantitative parameters measured (Table 2), there is no evidence of SCC susceptibility for the different stainless steel alloys AISI 304 and SS2, under the testing conditions. The half-cell potential values are compatible with a passive state. The slight evolution, towards most negative values, observed during the tests, may result from the effect of deformation of the passivation film due to the imposed stress.

The SS1 stainless steel tensile stress-time curves in both environments tested are characteristic of a brittle rupture (Fig. 1). The quantitative parameters from the SSRT in solution show a slight decrease comparatively to those obtained with the test in air. The potential-time curve shows a sharp potential drop, which indicates the initiation of corrosion of this stainless steel just before the mechanical rupture, at the end of the test.

Fig. 1 also shows some examples of scanning electron microscopy images on the fracture surface of the stainless steel tensile specimens obtained by test with the lowest crosshead rate in solution.

The stainless steel AISI 304 and SS2 specimens, tested in air and in solution, show a cup and cone fracture surface characteristic of a ductile fracture. The rupture begins at the middle of the cross section, with formation of a fibrous zone, and propagates towards the specimen surface with formation of a conical shear-lip zone.

The SEM fractographic analysis (Fig. 2) shows that the rupture mechanism for the SS1 stainless steel alloy presents different features in the two environments (either in air or in solution). The specimens tested in air show a mechanism of fracture by transgranular cleavage. The fracture surface is roughly plan and perpendicular to the tensile stress direction and develops with a very low section reduction. The specimens tested in solution show, besides the propagation zone with transgranular cleavage, an initial zone with corrosion products and an intergranular rupture opposed to the final small shear-lip zone. These fractographic characteristics observed for SS1 stainless steel confirm the stress corrosion susceptibility presented by this alloy.

There are several possible causes for the different behavior of this stainless steel alloy under the distinct testing conditions. However, there is a lack of experimental evidence to support any of them. According to Scully, in view of the model that indicates the transient dissolution amplitude and repassivation rate as basic considerations to interpret SCC, the transgranular fracture can became intergranular in a solution that allows the passivation of the slip steps [11]. Altering the solution $\mathrm{pH}$ is expected to change the repassivation rate and then to modify the fracture mechanism. It is also conceivable that different types of passive film are formed under the distinct conditions. Another possible hypothesis, which is normally associated with a transgranular brittle fracture, is the hydrogen embrittlement that can assist the fracture by several mechanisms. Although this interpretation is the most likely one for the tests performed in air.

The interpretative comparison of the different alloys is even more complex since there are decisive differences between them, namely as regards composition and microstructure. The different ferrite volume content and morphology in the two high manganese alloys may interfere with their SCC resistance. Referring to composition, the different passive films formed in high manganese stainless steel alloys [12] may hinder their SCC resistance. Also the highest nitrogen content in the new alloys may have a harmful effect on their SCC resistance if the plastic deformation has a similar outcome to that reported by cold working [13]. 

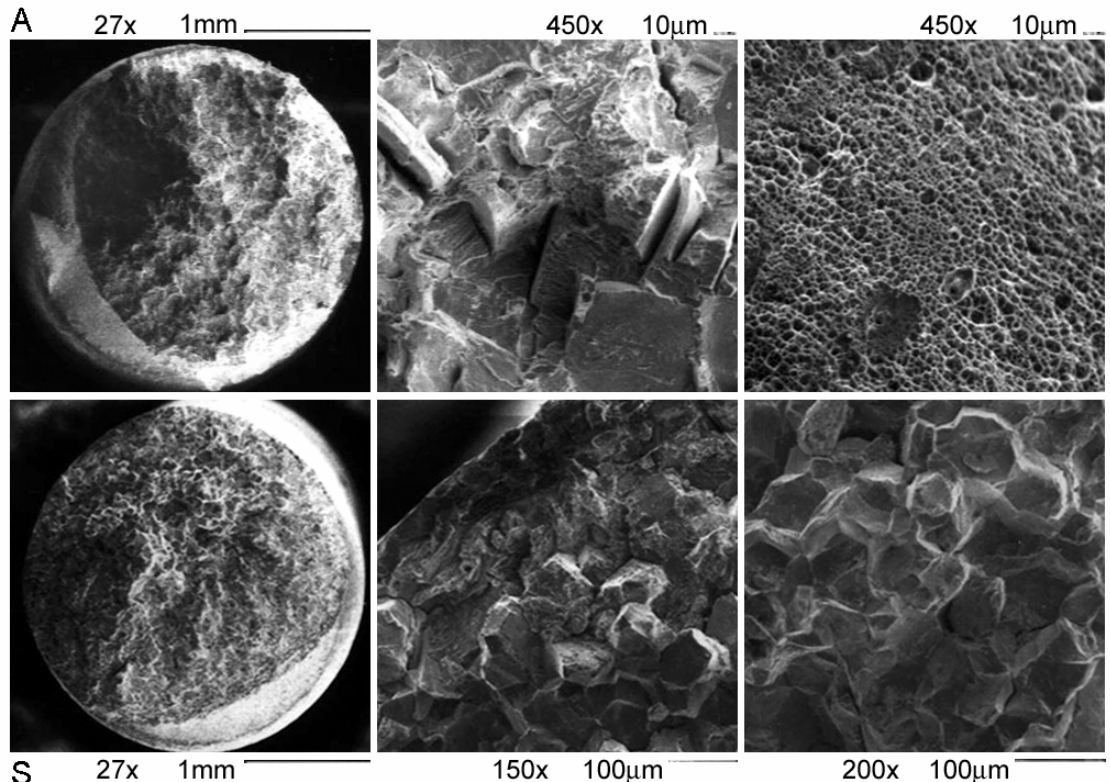

Figure 2 - SEM fractographs of SS1 stainless steel specimens tested in air (A) and in solution (S).

\section{Conclusions}

The new high manganese stainless steel alloy SS2, developed for the production of bars to reinforced concrete, presents an adequate resistance to SCC phenomenon in the alkaline environment contaminated with chlorides. Its corrosion resistance behavior under SSRT is similar to that of the AISI 304 stainless steel alloy.

The other SS1 Fe-Cr-Mn stainless steel alloy reveals SCC susceptibility in solution and also a brittle fracture under tensile stress even in air. These characteristics make this stainless steel alloy inadequate to be used in reinforced concrete.

Further research work in this area is essential to clarify the mechanisms of SCC corrosion so that the performance of newly developed alloys can be improved.

\section{Acknowledgements}

This study was developed for HIPER Project - "Increased infrastructure reliability by developing a low cost and high performance stainless steel rebars" - GDR1-2000-25601 from EC.

\section{References}

[1] J. A. González, S. Feliu, P. Rodriguez, E. Ramirez, C. Alonso and C. Andrade: Materials and Structures Vol. 29 (1996), p. 40.

[2] C. L. Page and K. W. J. Treadaway: Nature Vol. 297 (1982), p. 109.

[3] P. Pedeferri and L. Bertolini: La corrosion nel calcestruzzo e negli ambienti naturali (McGraw-Hill, Milano 1996).

[4] M. M. Salta: A utilização de armaduras de aço inoxidável como medida preventiva da corrosão em estruturas em ambiente marítimo (REPAR 2000, Lisboa 2000).

[5] C. J. Abbot: Concrete, May (1997), p. 28.

[6] Guidance on the use of stainless steel reinforcement (Concrete Society T. Report 51 1998).

[7] Corrosion of metals and alloys - Stress corrosion testing: Part 4 - Preparation and use of uniaxially loaded tension specimens (ISO 7539-4).

[8] Standard test method for determining average grain size (ASTM E 112-96).

[9] Standard test methods for determining the inclusion content of steel (ASTM E 45-97 (2002)).

[10] Corrosion of metals and alloys - Stress corrosion testing: Part 7 - Slow strain rate testing (ISO 75397).

[11] J. C. Scully: Corrosion Science Vol. 20 (1980), p. 997.

[12] A. Devasenapathi, M. Asawa: Journal of Materials Science Vol. 34 (1999), p. 5847.

[13] U. K. Mudali, P. Shankar, S. Ningshen, R. K. Dayal, H. S. Khatak, B. Raj: Corrosion Science Vol. 44 (2002) p. 2183. 